\title{
Congenital Horner's Syndrome and Internal Carotid Artery Hypoplasia
}

\author{
Jose Danilo B. Diestro (10, Irene Vanek, Amy Lin, Julian Spears
}

Keywords: Neurology - clinical, Neuro-ophthamology, Neuroimaging

doi:10.1017/cjn.2020.145

Can J Neurol Sci. 2021; 48: 112-113

Congenital Horner's syndrome is characterized by the presence of ipsilateral miosis, ptosis, facial anhidrosis, and iris hypochromia. ${ }^{1}$ A few case reports have found the condition to co-exist with other rare congenital entities involving the internal carotid artery (ICA): agenesis, aplasia, or hypoplasia. ${ }^{2-4}$
We present a case of a healthy 21-year-old male who was found to have a left eye ptosis during a routine consult with his family physician. Subsequently, an ophthalmologist made the diagnosis of Horner's syndrome. After neurovascular imaging identified a small left ICA, he was referred to our institution for a

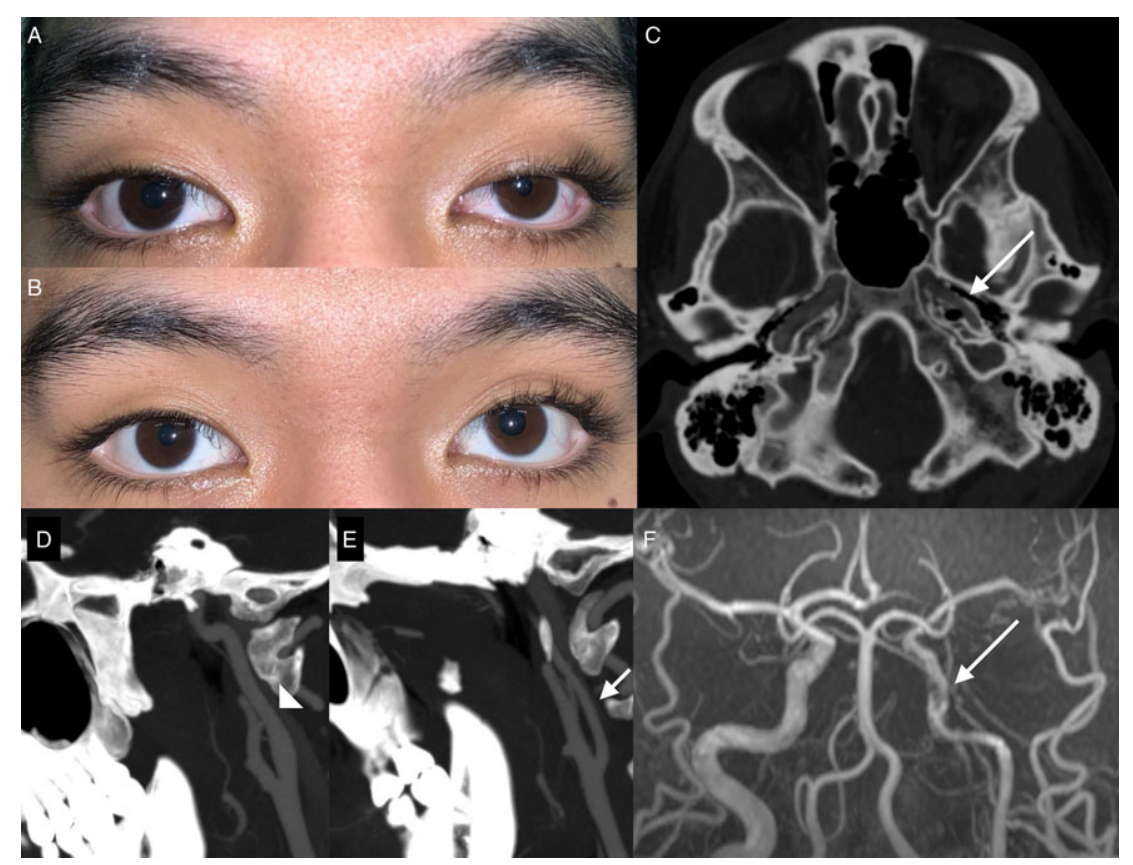

Figure 1: Key clinical and radiologic findings. (A) Baseline findings showing ptosis, upside down ptosis, miosis, and subtle iris hypopigmentation of the left eye. (B) Thirty minutes after instillation of apraclonidine drops the left pupil is now larger than the right with significant decrease in ptosis confirming the presence of a preganglionic Horner's syndrome. (C) Cranial computed tomography $(C T)$ scan showing a hypoplastic left internal carotid artery (ICA) and carotid canal (arrow). (D-E) Sagittal views taken at the carotid bifurcation showing a significantly hypoplastic left ICA, $3.1 \mathrm{~mm}$, (arrow) compared to the right ICA, $6.5 \mathrm{~mm}$, (arrow head). (F) Cranial time-of-fight magnetic resonance angiography demonstrating that the left ICA is narrowed throughout its entire length and has a segment between the petrous and cavernous segments where the artery appears discontinuous, with multiple small collaterals bridging the segments (arrow).

\footnotetext{
From the Division of Diagnostic and Therapeutic Neuroradiology, Department of Medical Imaging, St. Michael's Hospital, University of Toronto, Toronto, Ontario, Canada (JBD, AL, JS); and Division of Neurosurgery, Department of Surgery, University of Toronto, Toronto, Ontario, Canada (IV, JS)

Received April 22, 2020. Final Revisions Submitted May 23, 2020. Date of AcCeptance June 29, 2020.

Correspondence to: Jose Danilo B. Diestro, St. Michael's Hospital, University of Toronto, Medical Imaging Room CC3-141, 30 Bond Street, Toronto, ON M5B 1W8, Canada. Email: danni.diestro@gmail.com
} 
possible arterial dissection. He reports no anhidrosis on the left face. His past medical, family medical and personal social history were all unremarkable. He has no history of injury at birth and no relatives with documented anisocoria. However, his mother recalls that his left palpebral fissure had always been narrower than his right.

Pertinent ophthalmologic on the left eye includes the following: ptosis, upside down ptosis, miosis with dilation lag, and iris hypopigmentation. The measurements of the vertical palpebral fissure are as follows: OD $11 \mathrm{~mm}$ and OS $8 \mathrm{~mm}$. Pupils at baseline measured OD $5 \mathrm{~mm}$ and OS $3 \mathrm{~mm}$. No rapid afferent pupillary defect was noted. The presence of Horner's syndrome was confirmed after miosis resolved after instillation of apraclonidine drops (Figure 1(A) and (B)). The rest of his general and neurologic examination was unremarkable. Neurovascular imaging showed hypoplastic left carotid canal (Figure 1(C)), which is consistent with congenital hypoplasia of the LICA rather than dissection. The left ICA was hypoplastic throughout its entire length (Figure 1(D)-(F)). He was subsequently discharged from our clinic.

Horner's syndrome occurs because of a disruption in the ipsilateral sympathetic pathway. In our patient, the absence of prominent facial anhidrosis clinches the diagnosis of a postganglionic lesion. The internal carotid artery and the sympathetic nervous system have different embryologic origins, the mesoderm (third aortic arch and dorsal aortae) and the neural crest, respectively. ${ }^{5}$ Defective molecular signaling in the embryologic period likely underlie the congenital co-occurrence the two conditions. Deprez et al. have proposed that all cases of ICA agenesis, aplasia, or hypoplasia may actually be accompanied by Horner's syndrome if carefully examined. ${ }^{2}$ The finding of heterochromia iridis in our patient is similar to other reported cases. $^{2-4}$ The common neural crest origin of the sympathetic nervous system ganglia and the iris melanocytes likely underlie this association. ${ }^{3}$

Congenital ICA agenesis, aplasia, and hypoplasia are usually incidental findings but have on occasion also been found to be associated with stroke and intracranial aneurysms. ${ }^{5}$ Our case highlights the importance of skull base imaging for diagnosing congenital etiologies of reduced ICA caliber. A narrowed carotid canal should not be present in acquired conditions such as dissections. $^{2-4}$

\section{Disclosures}

The authors have nothing conflicts of interest to disclose.

\section{Statement of Authorship}

JBD, AL, IV, and JS all made substantial contributions to the conception or design of the work; or the acquisition, analysis, or interpretation of data for the work and drafting the work or revising it critically for important intellectual content. JBD, AL, IV, and JS are all responsible for the final approval of the version to be published. JBD, AL, IV, and JS are all in agreement to be accountable for all aspects of the work in ensuring that questions related to the accuracy or integrity of any part of the work are appropriately investigated and resolved.

\section{REFERENCES}

1. Weinstein JM, Zweifel TJ, Thompson HS. Congenital Horner's syndrome. Arch Ophthalmol. 1980;98(6):1074-8. doi: 10.1001/ archopht. 1980.01020031064011

2. Deprez FC, Coulier J, Rommel D, Boschi A. Congenital Horner syndrome with heterochromia iridis associated with ipsilateral internal carotid artery hypoplasia. J Clin Neurol. 2015;11(2):192. doi: $10.3988 /$ jen.2015.11.2.192

3. Ryan FH, Kline LB, Gomez C. Congenital Horner's syndrome resulting from agenesis of the internal carotid artery. Ophthalmology. 2000;107(1):185-8. doi: 10.1016/S0161-6420(99)00006-8

4. Farhat W, Ahdab R, Hosseini H. Congenital agenesis of internal carotid artery with ipsilateral horner presenting as focal neurological symptoms. Vasc Health Risk Manag. 2011;7:37-40. doi: 10.2147/VHRM.S16642

5. Cohen JE, Gomori JM, Leker RR. Internal carotid artery agenesis: diagnosis, clinical spectrum, associated conditions and its importance in the era of stroke interventions. Neurol Res. 2010;32(10):1027-32. doi: 10.1179/016164110X12767786356273 